\title{
Selected Topics on Business Information Systems Research: Editorial Introduction to Issue 26 of CSIMQ
}

\author{
Ben Roelens ${ }^{\star}$ \\ Department of Information Science, Open University of the Netherlands, \\ Valkenburgerweg 177, 6419 AT Heerlen, The Netherlands \\ ben.roelens@ou.nl
}

Business Information Systems research deals with the conceptualization, development, introduction, maintenance and utilization of systems for computer-assisted information processing within companies and enterprise-wide networks [1, p.1]. This CSIMQ issue contains five articles that deal with various information system (IS) issues, including IS security, product-related ISs, blockchain technology and sensor technology. The call for this issue was particularly targeted towards extended articles of two workshops that were held in conjunction with the 13th IFIP WG 8.1 working conference on the Practice of Enterprise Modelling. The first is the BES 2020 workshop (i.e., 1st Workshop on Blockchain and Enterprise Systems), which has the ambition to change the way one thinks, designs and implements ISs. The second one is ManComp 2020 (i.e., 5th Workshop on Managed Complexity), which is focused on approaches and methods for managing the complexity of ISs and IS interaction within ecosystems.

- The first article is written by Julia Kaidalova, Kurt Sandkuhl and Ulf Seigerroth and is titled Product-IT inclusive Enterprise Architecture Management: An Approach based on Ecosystems, Customer Journey and Data-driven Business Opportunities. This article is focused on IS components that are integrated into smart connected products, which are used by an enterprise for value creation and delivery. The contribution of the article is methodological support for integrating those smart products within Enterprise Architecture. The contribution is based on TOGAF and ArchiMate, which are two standards in the Enterprise Architecture field.

- The second is authored by Anne Sofie Vingerhoets, Samedi Heng and Yves Wautelet and is titled Using $i^{*}$ and UML for Blockchain Oriented Software Engineering: Strengths, Weaknesses, Lacks and Complementarity. This contribution is an extended BES 2020 workshop paper that studies how $i^{*}$ and UML can be used to document a blockchain development project in Supply Chain Management. These models are applied in the context of a real-life case study called 'Farm-to-Fork' where a blockchain solution for the supply chain of farm animals is developed. This enables to compare the strengths and weaknesses of the languages used.

- The third contribution is a short article that is written by Johannes Rude Jensen, Victor von Wachter and Omri Ross and is titled An Introduction to Decentralized Finance (DeFi). This

\footnotetext{
* Corresponding author
}

(C) 2021 Ben Roelens. This is an open access article licensed under the Creative Commons Attribution License (http://creativecommons.org/licenses/by/4.0).

Reference: B. Roelens, "Selected Topics on Business Information Systems Research: Editorial Introduction to Issue 26 of CSIMQ," Complex Systems Informatics and Modeling Quarterly, CSIMQ, no. 26, pp. I-II, 2021. Available: https://doi.org/10.7250/csimq.2021-26.00 
article is an extension of the research presented at ManComp 2020 and positions decentralized financial applications in the context of blockchain technology. To this end, the authors provide a taxonomical overview of relevant agents, incentives and risks. Furthermore, key market categories and use-cases for DeFi applications are identified.

- The fourth is written by Wenjun Xiong, Simon Hacks and Robert Lagerström and is titled $A$ Method for Assigning Probability Distributions in Attack Simulation Languages. To realize a higher degree of IS resilience against cyber attacks, the researchers propose a method to add probability distributions to the steps and defenses of an attack simulation language. The method is illustrated and evaluated by modeling and simulating a known cyber attack in the Meta Attack Language.

- The last article of this issue is authored by Mubashrah Saddiqa, Marite Kirikova, Birger Larsen, Rikke Magnussen and Jens Myrup Pedersen and is titled Towards Using Sensors as Data Sources in Teaching: Requirements for School Curricula-Compatible Sensors. The ambition of this article is to foster digital skills in an educational context. To this end, qualitative and quantitative research techniques are used to define criteria for sensor technology, particularly for secondary school students. Besides this, a requirements model is developed for sensor classes that satisfy the compatibility criteria.

The CSIMQ editorial team thanks all authors for their valuable contribution and all the reviewers of this issue for their critical comments and improvement recommendations regarding the submissions.

\section{References}

[1] R. T. Wigand, P. Mertens, F. Bodendorf, W. König, A. Picot and M. Schumann, Introduction to Business Information Systems, P. Mertens, F. Bodendorf, W. König, A. Picot and M. Schumann Eds., Springer Berlin Heidelberg, 2003. Available: https://books.google.be/books?id=u-1rLZ_WqTwC 